\title{
Hastane yöneticilerinde tükenmişlik düzeyi
}

\section{Burnout level of hospital managers}

\section{Hatice Ulusoy*, Enis Baha Biçer, Nurperihan Karabulut}

Sağlık Yönetimi Bölümü (Yrd. Doç. Dr. H. Ulusoy, Öğr. Gör. E. B. Biçer, Arş. Gör. N. Karabulut), Cumhuriyet Üniversitesi Sağlık Bilimleri Fakültesi, TR-58140 Sivas

\section{Özet}

Amaç. Tükenmişlik düzeyi, hastane yöneticilerinin sunacakları hizmetleri bireysel ve kurumsal düzeyde etkileyen önemli bir faktördür. Bu araştırmanın amacı hastane yöneticilerinin tükenmişlik düzeyini saptamaktır. Yöntem. Sivas ilinde bulunan tam teşekküllü hastanelerde çalışan başhekim ve yardımcıları, başmüdür ve yardımcıları, başhemşire ve yardımcıları $(n=58)$ bu tanımlayıcı çalışmaya dahil edilmiştir. Çalışmanın verileri kişisel bilgi formu ve Maslach Tükenmişlik Envanteri ile Mayıs-Haziran 2011 tarihleri arasında toplanmıştır. Ankete cevap verme oranı \%82,7'dir Ölçeğin Cronbach alpha katsayısı 0,737 olarak saptanmıştır. Bulgular. Çalışmada yöneticilerin duygusal tükenme alt boyut puan ortalaması 10,70 $\pm 6,44$; duyarsızlaşma puan ortalaması 3,62 $\pm 2,50$ ve kişisel başarı puan ortalaması $24,56 \pm 3,57$ olarak saptanmıştır. Sonuç. Çalışma doğrultusunda hastane yöneticilerinin genel olarak tükenmişlik düzeylerinin yüksek olmadığı saptanmıştır.

Anahtar sözcükler: Tükenmişlik, hastane yöneticileri

\begin{abstract}
Aim. Burnout level is one of the important factors affecting the level of performance in hospital managers. The aim of this descriptive study is to identify burnout level of hospital managers. Method. All head of physicians, directors and nurses and their assistants $(n=58)$ working at general hospitals in Sivas city center were included in this descriptive study.. Data collection tool of this descriptive study was a personal information form and Maslach Burnout Inventory. Data were collected between May-June 2011. The response rate of the questionnaire was $82.7 \%$. Cronbach's alpha coefficient of the inventory was 0.737 . Results. It was found that burnout subscale average score of the managers was $1.70 \pm 6.44$, desensitization average score was $3.62 \pm 2.50$ and the personal achievement average score was $24.56 \pm 3.57$. Conclusion. In the light of these findings it can be concluded that the hospital managers' burnout level is not high.
\end{abstract}

Keyword: Burnout, hospital managers

Geliş tarihi/Received: 29 Kasım 2011; Kabul tarihi/Accepted: 18 Temmuz 2012

\section{*İletişim adresi:}

Dr. Hatice Ulusoy, Sağlık Yönetimi Bölümü, Cumhuriyet Üniversitesi Sağlık Bilimleri Fakültesi, TR-58140 Sivas. E-posta: hulusoy65@gmail.com

Bu çalışma 2011 yılında Fethiye'de düzenlenen 5. Sağlık ve Hastane İdaresi Kongresinde sözel bildiri olarak sunulmuştur.

\section{Giriş}

İlk kez 1974 yılında Freudenberger [1] tarafından kullanılan tükenmişlik kavramı, 1981 yılında Maslach ve Jackson [2] tarafından mesleği gereği insanlarla çalışan bireylerde sıklıkla gözlenen bir sendrom olarak tanımlanmıştır. Maslach ve Jackson [2]'a göre ilişkinin çoğunlukla hizmet verilen kişinin psikolojik sosyal veya fiziksel problemlerine odaklanmayı gerektirdiği mesleklerde kızgınlık, korku, ümidin ve güvenin kaybedilmesi 
gibi duygular yaşanabilir. Bu duyguların yarattığı stres ise zamanla tükenmişlik açısından bir risk oluşturur. Maslach ve Jackson [2] tarafindan duygusal tükenme, duyarsızlaşma ve kişisel başarı eksikliği olarak üç alt boyutta incelen tükenmişlik sendromunda, duygusal tükenme, kişinin yaptığ 1 iş nedeniyle kendisini aşırı yüklenilmiş ve tüketilmiş olarak hissetmesidir ve tükenmişliğin en önemli boyutunu göstermektedir. Duyarsızlaşma, kişinin bakım ve hizmet verdiklerine karşı- bu kişilerin kendilerine özgü birer birey olduklarını dikkate almaksızın- duygudan yoksun biçimde tutum ve davranışlar sergilemesini içerir. Kişisel başarı ise sorunların başarı ile üstesinden gelme ve kendini yeterli bulma olarak tanımlanır [2].

Tükenmişlik profesyonellerin işleri gereği karşılaştıkları kişilere karşı duyarsızlaşmaları, duygusal yönden kendilerini tükenmiş hissetmeleri ve kişisel başarı ve yeterlilik duygularının azalması şeklinde ortaya çıkar. Çalışılan grubun özellikleri, çevresel koşullar, çalışma koşulları gibi kuruma ait bazı bireysel özelliklerle ilişkili olarak gelişir. Tükenmişlik duygularının, bu tür sorunların yaşandığı ortamlarda her profesyonelde görülme olasılığı vardır [3]. Uluslararası literatürde oldukça zengin ve geniş boyutta çalışılan tükenmişlik konusu ile ilgili çalışmalara ülkemizde 1992 yılından sonra başlanmış olup özellikle son 15 yıl içinde sağlık personeli üzerindeki çalışmaların sayısı artmıştır. [4] Çalışmalar daha çok doktor ve hemşireler ve diğer sağlık çalışanlarını kapsamaktadır [3, 5-13]. Sağlık sektöründe hizmet verenler iş yoğunluğu, hastaların sorumluluğu, sürekli stresli ortamda bulunma, nöbet tutma gibi nedenlerle tükenmişliği oldukça yoğun bir şekilde yaşamaktadır. Sağlık çalışanları içinde hekimlerin ve özellikle hemşirelerin tükenmişlik açısından en riskli grup olduğu belirtilmektedir [14]. Bununla beraber sağlik hizmetlerinin etkin olarak yönetilmesinden birinci derecede sorumlu olan sağlık yöneticileri ise iş stresi yüksek olan grup olarak belirtilmektedir [15]. Ancak bu grubun yaşadığı tükenmiş̧lik boyutunu araştıran çalışmaların sayısı oldukça sınırlıdır [15, $16,17]$.

Tanımlayıcı olarak yapılan bu çalışmanın amacı Sivas il merkezinde bulunan hastanelerde çalışan hastane yöneticilerinin tükenmişlik düzeyini saptamaktır.

\section{Gereç ve yöntem}

Tanımlayıcı olarak yapılan bu çalışmanın evrenini, Sivas ilinde bulunan tam teşekküllü hastanelerde çalışan başhekim ve yardımcıları, başmüdür ve yardımcıları, başhemşire ve yardımcıları $(\mathrm{N}=58)$ oluşturmuştur. Çalışmanın verileri kişisel Bilgi Formu ve 22 soru ve üç alt boyuttan oluşan Maslach Tükenmişlik Envanteri (MTE) ile Mayıs- Haziran 2011 tarihleri arasında toplanmıştır. Orijinali Maslach ve Jackson [2] tarafindan geliştirilen ölçeğin Türkiye'de geçerlilik ve güvenilirlik çalışması Ergin [14] tarafından yapılmıştır. Ölçeğin alt boyutları "duygusal tükenme" (DT), "duyarsızlaşma" (D) ve "kişisel başarı" (KB) olarak tanımlanmaktadır.

MTE'de yer alan sorular beşli Likert tipinde hazırlanmış olup "Hiçbir zaman (0)- Her zaman (4) puan olarak puanlanmaktadır. MTE'nin Türkçe versiyonunda alt boyutlardan elde edilen sonuçları değerlendirmek için bir kesme puanı bulunmayıp (9) duygusal tükenme ve duyarsızlaşma alt boyutlarında yüksek puanlar yüksek tükenmişliği, kişisel başarı alt grubunda ise düşük puanlar yüksek tükenmişliği göstermektedir. Ölçeğin Cronbach alpha katsayısı 0,737 olarak saptanmıştır. Alt boyutlardaki Cronbach Alpha katsayıları ise DT boyutunda 0,885; Duyarsızlaşma boyutunda 0,643 ve KB boyutunda ise 0,670 olarak saptanmıştır.

Çalışmada, Rektörlük, İl Sağlık Müdürlügü gibi gerekli yerlerden yazılı onay alınmış, veri toplama formlarının uygulamasına geçilmeden önce yöneticilerle yüz yüze görüşülerek çalışmanın amacı ve gerekli diğer konularda açıklamalar yapılmıştır. Araştırmaya katılım için yöneticilerden sözel onamları alınmıştır. Yöneticilerin çalışmaya katılım oranı \% 82,7 olarak gerçekleşmiştir. Çalışmada verilerin analizi için SPSS 14.0 programı kullanılmıştır. Veriler ortalamalar üzerinden değerlendirilmiştir. 


\section{Bulgular}

Araştırmaya katılan toplam 48 hastane yöneticisinin üçte ikisinin $(\% 66,7)$ erkeklerden oluştuğu, 1 kişi hariç tamamının evli olduğu, \%45,8'inin 36-45 yaş grubunda olduğu, (yaş ortalaması 44,5: $\min 36, \max 63) \% 39,6$ 'sının hastane müdürü ve yardımcılarından oluştuğu, \%52,1'inin lisans düzeyinde eğitim aldığı, \%39,6'sının gelir düzeyinin $2500 \mathrm{TL}$ altında olduğu saptanmıştır. Yöneticilerin \%50' si mesleğinde 21 yıl ve üzeri çalıştığını, $\% 52,1$ 'i 1-5 yıl arasında yönetici pozisyonunda olduğunu, \%47,9'u kendilerine bağlı personel sayısının 51-299 arasında olduğunu, \%79,2'si haftalık çalışma saatinin ortalama 40-49 saat aralığında olduğunu ifade etmiştir.

Çalışmada Üniversite Hastanesinde çalışan 1 başhekim yardımcısı ve 2 müdür yardımcısı dışında (başhemşirelik hariç) diğer hastanelerde kadın yönetici bulunmadığı diğer bir deyişle başhemşirelik grubu hariç tutulduğunda yöneticilerin \%91,4'ünün erkeklerden oluştuğu saptanmiştır.

Tablo 1. Yöneticilerin sosyo-demografik özelliklerinin dağılımı.

\begin{tabular}{|c|c|c|}
\hline Cinsiyet & $\mathbf{n}$ & $\%$ \\
\hline Kadın & 16 & 33,3 \\
\hline Erkek & 32 & 66,7 \\
\hline \multicolumn{3}{|l|}{ Medeni durum } \\
\hline Evli & 47 & 97,9 \\
\hline Bekar & 1 & 2,1 \\
\hline \multicolumn{3}{|l|}{ Yaş grubu } \\
\hline 35 ve alt 1 & 7 & 14,6 \\
\hline $36-40$ & 11 & 22,9 \\
\hline $41-45$ & 11 & 22,9 \\
\hline $46-50$ & 7 & 14,6 \\
\hline 50 ve üzeri & 12 & 25,0 \\
\hline \multicolumn{3}{|l|}{ Eğitim durumu } \\
\hline lise+önlisans & 7 & 14,6 \\
\hline lisans & 25 & 52,1 \\
\hline lisansüstü & 16 & 33,3 \\
\hline \multicolumn{3}{|l|}{ Yönetim görevi } \\
\hline Başhekim ve yard. & 16 & 33,3 \\
\hline Başhemșire ve yard. & 13 & 27,1 \\
\hline Müdür ve yard. & 19 & 39,6 \\
\hline \multicolumn{3}{|l|}{ Aylık gelir düzeyi (TL) } \\
\hline $1500-2499$ & 19 & 39,6 \\
\hline $2500-3499$ & 12 & 25,0 \\
\hline $3500-4499$ & 6 & 12,5 \\
\hline 4500 ve üzeri & 11 & 22,9 \\
\hline \multicolumn{3}{|l|}{ Meslekte çalıșma yılı } \\
\hline 15 yil ve alt1 & 10 & 20,8 \\
\hline $16-20$ & 14 & 29,2 \\
\hline 21 yıll ve üzeri & 24 & 50,0 \\
\hline \multicolumn{3}{|c|}{ Yönetici olarak çalışma yılı } \\
\hline $1-5$ yll & 25 & 52,1 \\
\hline $6-10$ y1l & 10 & 20,8 \\
\hline 11 y1l ve üzeri & 13 & 27,1 \\
\hline \multicolumn{3}{|l|}{ Bağlı personel sayısı } \\
\hline 50 ve altý & 13 & 27,1 \\
\hline $51-299$ & 23 & 47,9 \\
\hline 300 ve üzeri & 12 & 25,0 \\
\hline \multicolumn{3}{|l|}{ Haftalık çalışma süresi } \\
\hline $40-44$ saat & 18 & 37,5 \\
\hline 45-49 saat & 20 & 41,7 \\
\hline 50 saat ve üstü & 10 & 20,8 \\
\hline Toplam & 48 & 100,0 \\
\hline
\end{tabular}


Tablo 2. Yöneticilerin MTE tükenmişlik puanları.

\begin{tabular}{lllll}
\hline & Olası & \multicolumn{3}{c}{ Gözlenen Değerler } \\
& Min-Max & Min-Max & Ort & Ss \\
\hline Duygusal Tükenme & $0-36$ & $0-25$ & 10,70 & 6,44 \\
Duyarsızlaşma & $0-20$ & $0-10$ & 3,62 & 2,50 \\
Kişisel Başarı & $0-32$ & $17-32$ & 24,56 & 3,57 \\
\hline
\end{tabular}

Tablo 2‘de yöneticilerin MTE tükenmişlik puanları verilmiştir. Buna göre yöneticilerin duygusal tükenme alt boyutundaki ortalama puanı, 10,70 $\pm 6,44$; duyarsızlaşma alt boyutundaki ortalama puanı $3,62 \pm 2,50$ ve kişisel başarı boyutundaki ortalama puanı da 24,56 $\pm 3,57$ olarak belirlenmiştir.

Tablo 3. Yöneticilerin sosyo-demografik özelliklerine göre tükenmişlik puanları.

\begin{tabular}{|c|c|c|c|c|c|c|c|c|c|c|}
\hline \multirow{2}{*}{\multicolumn{2}{|c|}{$\mathbf{N}$}} & \multicolumn{3}{|c|}{ Duygusal tükenme } & \multicolumn{3}{|c|}{ Duyarsızlaşma } & \multicolumn{3}{|c|}{ Kişisel başarı } \\
\hline & & Ort & Ss & Min-Max & Ort & Ss & Min-Max & Ort & Ss & Min-Max \\
\hline \multicolumn{11}{|l|}{ Cinsiyet } \\
\hline Kadın & 16 & 11,93 & 5,60 & $6-25$ & 4,0 & 2,09 & $0-8$ & 24,25 & 3,71 & $17-30$ \\
\hline Erkek & 32 & 10,09 & 6,83 & $0-24$ & 3,43 & 2,69 & $0-10$ & 24,71 & 3,55 & $19-32$ \\
\hline \multicolumn{11}{|l|}{ Yaş grubu } \\
\hline 35 yaş ve altı & 7 & 8,57 & 4,89 & $0-16$ & 4,14 & 2,60 & $0-8$ & 24,28 & 3,25 & $19-30$ \\
\hline $36-40$ yaş & 11 & 13,09 & 5,35 & $6-21$ & 4,81 & 2,18 & $0-7$ & 22,36 & 3,44 & $17-29$ \\
\hline $41-45$ yaş & 11 & 13,45 & 8,29 & $1-25$ & 4,09 & 2,30 & $0-7$ & 23,90 & 3,01 & $20-31$ \\
\hline 46-50 yaş & 7 & 12,00 & 5,88 & $3-21$ & 3,0 & 1,91 & $0-5$ & 24,00 & 2,44 & $21-27$ \\
\hline 50 yaş ve üzeri & 12 & 6,05 & 4,52 & $0-17$ & 2,16 & 2,75 & $0-10$ & 27,66 & 3,25 & $22-32$ \\
\hline \multicolumn{11}{|c|}{ Medeni durum } \\
\hline Evli & 47 & 10,80 & 6,47 & $0-25$ & 3,59 & 2,52 & $0-10$ & 24,59 & 3,60 & $17-32$ \\
\hline Bekar & 1 & 6,00 & - & $6-6$ & 5,00 & - & $5-5$ & 23,00 & - & $23-23$ \\
\hline \multicolumn{11}{|l|}{ Ĕgitim } \\
\hline Lise-Önlisans & 7 & 14,00 & 7,30 & $4-25$ & 4,14 & 1,34 & $2-6$ & 24,85 & 2,19 & $22-27$ \\
\hline Lisans & 25 & 10,00 & 5,53 & $0-21$ & 3,20 & 2,58 & $0-10$ & 25,44 & 3,67 & $17-32$ \\
\hline Lisansüstü & 16 & 10,37 & 7,33 & $0-24$ & 4,06 & 2,76 & $0-8$ & 23,06 & 3,58 & $19-32$ \\
\hline \multicolumn{11}{|l|}{ Gelir durumu } \\
\hline $1500-2499$ & 19 & 11,78 & 6,38 & $3-25$ & 3,73 & 2,44 & $0-10$ & 24,84 & 3,56 & $17-32$ \\
\hline 2500-3499 & 12 & 10,41 & 7,27 & $0-24$ & 4,00 & 2,98 & $0-8$ & 24,83 & 3,63 & $19-31$ \\
\hline $3500-4499$ & 6 & 10,00 & 4,97 & $3-17$ & 2,33 & 1,36 & $1-4$ & 26,00 & 3,63 & $21-30$ \\
\hline 4500 ve üzeri & 11 & 9,54 & 6,87 & $0-23$ & 3,72 & 2,61 & $0-7$ & 23,00 & 3,46 & $19-32$ \\
\hline
\end{tabular}

Tablo 3'de yöneticilerin sosyo-demografik özelliklerine göre tükenmişlik puanları verilmiştir. Yukarıda da belirtildiği gibi MTE'ne göre DT ve D alt boyutlarında yüksek puanlar, yüksek tükenmişliği, KB alt grubunda düşük puanlar yüksek tükenmişliği göstermektedir. Buna göre, DT puanı açısından kadınların $(11,93 \pm 5,60)$; $41-45$ yaş

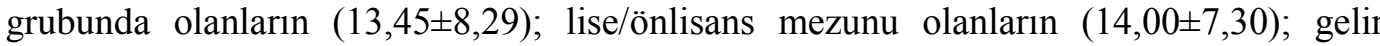
düzeyi $2500 \mathrm{TL}$ altında olanların $(11,78 \pm 6,38)$ puanları diğer gruplara göre daha yüksektir. Benzer şekilde Duyarsızlaşma puanı açısından da kadınların $(4,00 \pm 2,09)$; 36 40 yaş grubunda olanların $(4,81 \pm 2,18)$ ve lise/önlisans mezunu olanların $(4,14 \pm 1,34)$ ve gelir düzeyi 2500-3499 TL arasında olanların $(4,00 \pm 2,98)$ puanları diğer gruplara göre daha yüksektir. KB puanları açısından kadınların $(24,25 \pm 3,71)$; 36-40 yaş grubunda olanların $(22,36 \pm 3,44)$; lisansüstü düzeyde eğitim alanların $(23,06 \pm 3,58)$ ve $4500 \mathrm{TL}$ üzerinde aylık geliri olanların $(23,00 \pm 3,46)$ puanları diğer gruplara göre daha düşük saptanmıştır. Tablo 4'te görüldüğü gibi, DT açısından haftalık çalışma saati 50 saat olanların $(12,90 \pm 5,60)$, başhemşire ve yardımcılarının $(13,00 \pm 5,64)$, meslekte çalışma süresi 16-20 yıl arasında olanların $(13,57 \pm 7,91)$ yönetici olarak çalışma süresi 6-10 yıl arasinda olanların $(12,70 \pm 7,52)$ ve 300 'den fazla personelden sorumlu olanların $(11,75 \pm 7,71)$ DT puanları diğer gruplara göre daha yüksektir. Duyarsızlaşma puanı 
açısından, haftalık çalışma saati 50 saat olanların $(5,00 \pm 2,10)$, başhemşire ve yardımcılarının $(4,46 \pm 1,76)$, meslekte çalışma süresi 15 yıl ve altında olanların $(4,70 \pm 2,40)$, yöneticilik deneyimi 1-5 yıl arasında olanların $(3,80 \pm 2,39)$ ve 300 'den fazla personelden sorumlu olanların $(4,08 \pm 2,68)$ duyarsızlaşma puanları diğer gruplara göre daha yüksektir. KB puanları açısından haftada ortalama 45-49 saat çalışanların $(25,55 \pm 3,28)$, Başhekim ve yardımcılarının $(23,25 \pm 3,43)$, meslekte çalışma süresi 15 yıl ve daha az olanların, $1-5$ yıldır yöneticilik yapanların $(23,72 \pm 3,58)$ puanları diğer gruplara göre daha düşüktür.

Tablo 4. Yöneticilerin iş yaşamındaki özelliklerine göre tükenmişlik puanları.

\begin{tabular}{|c|c|c|c|c|c|c|c|c|c|c|}
\hline & \multicolumn{4}{|c|}{ Duygusal tükenme } & \multicolumn{3}{|c|}{ Duyarsızlaşma } & \multicolumn{3}{|c|}{ Kişisel başarı } \\
\hline & $\mathbf{N}$ & Ort & Ss & Min-Max & Ort & Ss & Min-Max & Ort & Ss & Min-Max \\
\hline \multicolumn{11}{|c|}{ Haftalık çalışma süresi } \\
\hline $40-44$ saat & 18 & 7,83 & 4,93 & $0-17$ & 2,77 & 2,18 & $0-7$ & 25,55 & 3,76 & $21-32$ \\
\hline $45-49$ saat & 20 & 12,20 & 7,30 & $0-25$ & 3,70 & 2,73 & $0-10$ & 23,80 & 3,28 & $17-30$ \\
\hline 50 saat ve üstü & 10 & 12,90 & 5,60 & $7-24$ & 5,00 & 2,10 & $1-7$ & 24,30 & 3,74 & $19-30$ \\
\hline \multicolumn{11}{|l|}{ Meslek } \\
\hline Başhekim ve yard. & 16 & 10,62 & 7,32 & $0-24$ & 3,87 & 2,57 & $0-7$ & 23,25 & 3,43 & $19-32$ \\
\hline Başhemşire ve yard. & 19 & 13,00 & 5,64 & $7-25$ & 4,46 & 1,76 & $2-8$ & 23,53 & 3,45 & $17-30$ \\
\hline Müdür ve yard. & 13 & 9,21 & 6,04 & $0-21$ & 2,84 & 2,75 & $0-10$ & 26,36 & 3,14 & $21-32$ \\
\hline \multicolumn{11}{|c|}{ Meslekte çalışma süresi } \\
\hline 15 y1l ve altı & 10 & 9,20 & 4,63 & $0-16$ & 4,70 & 2,40 & $0-8$ & 22,40 & 2,27 & $19-25$ \\
\hline $16-20$ y1l & 14 & 13,57 & 7,91 & $1-25$ & 4,14 & 2,56 & $0-7$ & 23,57 & 3,56 & $17-30$ \\
\hline 21 yıl ve üzeri & 24 & 9,66 & 5,82 & $0-21$ & 2,87 & 2,36 & $0-10$ & 26,04 & 3,47 & $21-32$ \\
\hline \multicolumn{11}{|c|}{ Yönetici olarak çalışma süresi } \\
\hline $1-5$ y1l & 25 & 10,52 & 6,77 & $0-25$ & 3,80 & 2,39 & $0-8$ & 23,72 & 3,58 & $17-32$ \\
\hline $6-10$ y1l & 10 & 12,70 & 7,52 & $1-24$ & 3,30 & 2,83 & $0-7$ & 25,10 & 3,54 & $19-30$ \\
\hline 11 y1l ve üzeri & 13 & 9,53 & 4,87 & $3-19$ & 3,53 & 2,63 & -10 & 25,76 & 3,41 & $21-32$ \\
\hline \multicolumn{11}{|c|}{ Bağlı personel sayısı } \\
\hline 50 ve alt 1 & 13 & 9,84 & 5,75 & $1-21$ & 3,53 & 2,29 & $1-7$ & 24,53 & 3,99 & $19-32$ \\
\hline 51 ve 299 & 23 & 10,65 & 6,32 & $0-25$ & 3,43 & 2,62 & $0-10$ & 24,47 & 3,35 & $17-30$ \\
\hline 300 ve üzeri & 12 & 11,75 & 7,71 & $0-23$ & 4,08 & 2,64 & $0-8$ & 24,75 & 3,84 & $19-32$ \\
\hline
\end{tabular}

\section{Tartışma}

Sivas il merkezinde bulunan hastanelerde çalışan hastane yöneticilerinin tükenmişlik düzeyini saptamak amacıyla yapılan bu çalışmada, yöneticilerin yaş ortalaması 44,5 olup, katılımcıların yaklaşık yarısı 36-45 yaş aralığındadır. Erkek yöneticilerin çalışmaya katılanların üçte ikisini oluşturduğu ancak başhemşirelik grubu hariç tutulduğunda yöneticilerin \%91,4'ünün erkeklerden oluş̧tuğu saptanmıştır.

Yöneticilerin yarısının mesleklerinde çalışma süresinin 21 yıl ve üzerindedir ancak \%52,1'inin yönetici olarak çalışma yılları 1-5 yıl arasındadır. Yöneticilerin büyük bir çoğunluğunun $(\% 79,2)$ haftalık çalışma saati ortalama $40-49$ saat aralığındadır.

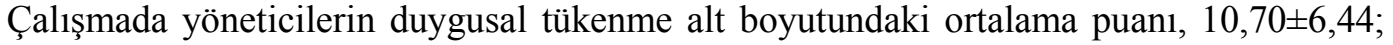
duyarsızlaşma alt boyutundaki ortalama puanı 3, 62 $\pm 2,50$ ve kişisel başarı boyutundaki

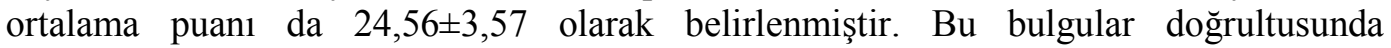
araştırmaya katılan yöneticilerin DT ve duyarsızlaşma puanlarının düşük, kişisel başarı puanlarının oldukça yüksek olduğu dolayısıyla hastane yöneticilerinin tükenmişlik ve duyarsızlaşma düzeyinin düşük olduğunu ve kendilerini başarılı olarak algıladıklarını söyleyebiliriz.

Öztürk ve ark [15]'nın Kayseri'de görev yapan sağlık yöneticileri ile yaptıkları çalışmanın bulguları ile çalışmamızın bu bulguları birbirine oldukça benzer şekildedir. Türkiye genelinde çalışan 52 il sağlık müdürü ile yapılan bir çalışmada [17] ise sağlık müdürlerinin kişisel başarı puanı çalışmamızla paralel bir bulguya sahipken, duygusal 
tükenme $(13,88)$ ve duyarsızlaşma puanı $(5,11)$ çalışmamıza göre biraz daha yüksek bulunmuştur.

Tükenmişlik düzeyi ile sosyo demografik veriler arasındaki ilişki incelendiğinde, sağlık personeli ile yapılan çalışmalarda genellikle kadınların erkeklere oranlara daha yüksek düzeyde tükenmişlik yaşadıkları saptanmıştır $[10-12,18]$. Kadınların iş dışındaki yaşamlarında toplumsal rol ve sorumluluklarının fazla olması tükenmişlik düzeylerinin erkeklere göre daha yüksek olmasının nedeni olabilir.

Yaş ile tükenmişlik arasındaki ilişki değerlendirildiğinde, literatürde genç yaşta olanların ve meslekteki deneyim süresi daha az olanların tükenmişlik yönünden riskli gruplar olduğu belirtilmektedir $[4,15,19,20]$.

Çalışmamızda da 50 yaş ve üzerinde olan yöneticilerin, meslekte çalışma süresi 21 yıl ve üzeri olanların ve yönetici olarak çalışma süreleri 11 yıl ve üzeri olanların, bu bilgiyi destekler şekilde tükenmişlik ve duyarsızlaşma puan ortalamalarının daha düşük olduğu, KB ortalamalarını yüksek olduğu gözlemlenmiştir. Meslek grupları açısından incelendiğinde tükenmişlik konusunda hastane müdür ve yardımcıları ile yapılmış yalnızca bir çalışmaya [15] rastlanmış olup, çalışmamızın bulgularına paralel şekilde hastane müdür ve yardımcılarının tükenmişlik, duyarsızlaşma düzeyi hekim ve hemşire yöneticilere göre daha düşük, KB düzeylerini algılamaları daha yüksektir.

Çalışmamızda literatürü destekler şekilde, başhemşire ve başhemşire yardımcısı olarak görev yapan grubun DT ve duyarsızlaşma puanlarının diğer iki gruptan yüksek olduğu, hekimlerin KB puanının hemşirelerden biraz daha düşük olduğu saptanmıştır. Tükenmişlik konusu hekim ve hemşireler açısından incelendiğinde, Öztürk ve ark. [15]'nın çalışması hariç pek çok çalışmada hemşirelerin doktorlara göre daha fazla DT ve duyarsızlaşma yaşadıkları, KB düzeylerini doktorlara göre daha düşük algıladıkları saptanmıştır [3, 10-12].

Literatürde hemşirelerle MTE kullanılarak yapılan diğer bazı çalışmalar incelendiğinde de $[9,18,20,21]$ hemşirelerin DT ve duyarsızlaşma puan ortalamalarına ait puanların yüksek, KB puanlarının düşük olduğu saptanmıştır. Hemşirelerin iş yüklerinin fazla olması, nöbet usulü çalışma, çalışma ortamından memnun olmama, rol çatışması ve rol belirsizliği yaşama, hastalarla ve ekiple olan iletişim sorunları, gelir durumu ve mesleği isteyerek seçme düzeylerinin düşük olması gibi nedenler hemşirelerin tükenmişlik düzeylerinin yüksek olmasının nedenleri arasında sayılabilir [4, 22].

Hekimlerin tükenmişlik düzeyini araştıran çalışmalar incelendiğinde ise $[5-8,13,19]$ özellikle asistan hekimlerin DT puan ortalamalarının çalışmamıza katılan yönetici hekimlerle karşılaştırıldığında daha yüksek olduğu saptanmıştır.

Konuyla ilgili aynı ölçüm aracı kullanılarak yapılan çalışmalar incelendiğinde dikkat çeken bir nokta ise yönetim görevi olan ve olmayan hekimlerden elde edilen DT puan ortalamalarıdır. Örneğin TTB'nin (Türk Tabipleri Birliği) [19] Türkiye genelinde 1754 hekimle yaptığı bir çalışmada, hekimlerin DT ortalaması 15,48; Sayıl ve ark. [3]'nın çalışmasında 19, Erşan ve ark. [12]'nın çalışmasında 24,7'dir. Çalıştıkları kurumda bir yönetim görevi olmayan hekimlerde Kurçer'in [5] çalışmasında 17,0, Özyurt ve ark. [7]'nın çalışmasında 13,9 iken yönetim görevi olan hekimlerde Kurçer'in çalışmasında 14,3; Özyurt ve ark. [7]'nın çalışmasında 12,41 bizim çalışmamızda ise 10,62'dir. Sonuç olarak, beklenenin aksine yönetici olarak çalışan hekimlerin, yönetim görevi olmayanlara göre daha az tükenmişlik yaşadıkları söylenebilir.

Çalışmamızda, kendisine bağlı personel sayısı ve haftalık çalışma saati artıkça DT ve duyarsızlaşmanın yanı sıra KB'nın da arttığı, saptanmıştır. Yöneticilerin sorumluk alanlarının ve iş yüklerinin artması, çalışma sürelerinin uzaması bir stresör olarak düşünüldüğünde bu bulgu beklendik bir durum olarak yorumlanabilir. 
Sonuç olarak, hastane yöneticilerinin genel olarak tükenmişlik yaşamadıkları saptanmıştır. Bununla birlikte başhemşire ve yardımcıları duygusal tükenme ve duyarsızlaşmayı en yüksek düzeyde yaşayan grupken başhekim ve yardımcılarının kişisel başarı algılamaları diğer gruplardan daha düşüktür. Hastane müdür ve yardımcılarının DT ve duyarsızlaşma yaşamadıkları kişisel başarı algılarının yüksek olduğu saptanmıştır.

\section{Kaynaklar}

1. Freudenberger HJ. Staff burn-out. Journal of Social Issues 1974; 30: 159-65.

2. Maslach C, Jackson SE. The Measurement of Experienced Burnout. Journal of Occupational Behaviour 1981; 2: 99-113.

3. Sayıl I, Haran S, Ölmez Ş, Özgüven HD. “Ankara Üniversitesi Hastanelerinde çalışan doktor ve hemşirelerin tükenmişlik düzeyleri” Kriz dergisi 5: 71-7.

4. Günüşen N.P Üstün B. "Türkiye'de İkinci Basamak Sağlık Hizmetlerinde Çalışan Hemşire ve Hekimlerde Tükenmişlik: Literatür İncelenmesi”, DEUHYO ED 2010; 3: 40-51.

5. Kurçer M. Harran Üniversitesi Tıp Fakültesi hekimlerinin iş doyumu ve tükenmişlik düzeyleri. Harran Üniversitesi Tip Fakültesi Dergisi 2005; 2: 10-5.

6. Çan E, Topbaş M, Yavuzyılmaz A, Çan G, Özgün Ş. Karadeniz Teknik Üniversitesi Tıp Fakültesindeki araştırma görevlisi hekimlerin tükenmişlik sendromu ile iş doyumu düzeyleri ve ilişkili faktörler. Ondokuz Mayıs Üniversitesi Tıp Dergisi 2006; 23: 17-74.

7. Özyurt A, Hayran O, Sur H. Predictors of burnout and job satisfaction among Turkish physicians. QJM 2006; 99: 161-9.

8. Erol A, Sarıçiçek A, Gülseren Ş. Asistan hekimlerde tükenmişlik: İş doyumu ve depresyonla ilişkisi. Anadolu Psikiyatri Derg 2007; 8: 241-7.

9. İlhan MN, Durukan E, Taner E, Maral I, Bumin MA. Burnout and its correlates among nursing staff: questionnaire survey. J Adv Nurs 2007; 61: 100-6.

10. Kocabıyık Z, Çakıcı E. Sağlık çalışanlarında tükenmişlik ve iş doyumu. Anadolu Psikiyatri Dergisi 2008; 9: 112-8.

11. Tunc T, Kutanis RO. Role conflict, role ambiguity, and burnout in nurses and physicians at a university hospital in Turkey. Nurs Health Sci 2009; 11: 410-6.

12. Erşan E, Doğan O, Doğan S. Analyzing of factors related to burn out in health professionals of Sivas Numune Hospital. Cumhuriyet T1p Dergisi 2011; 33: 33-41.

13. Dikmetaş E, Top M, Ergin G. An examination of mobbing and burnout of residents. Türk Psikiyatri Derg 2011; 22: 137-49.

14. Ergin C. Doktor ve hemşirelerde tükenmişlik ve Maslach tükenmişlik ölçeğinin uyarlanmasi. VII. Ulusal Psikoloji Kon-gresi (Kongre kitabı). Ankara: 22-25 Eylül 1992; 143-54.

15. Öztürk A, Tolga Y, Şenol V, Günay O. Kayseri ilinde görev yapan sağlık idarecilerinin tükenmişlik düzeylerinin değerlendirilmesi. Erciyes Tıp Dergisi 2008; 30: 92-9.

16. Demirbaş AR. Üç farklı hastanenin yöneticilerinin ve klinikte çalışan sağlık personelinin tükenmişlik durumları. Ankara Üniversitesi Sağlık Yönetimi Bölümü Yüksek Lisans Tezi 2006

17. Keskin G, Çınar Z, Alparslan Ö, Özmercan V. Türkiye'deki il sağlık müdürlerinin liderlik davranışlarının iş doyumları ve tükenmişlik düzeyleri üzerine etkileri II. Uluslararası Sağlikta Performans ve Kalite Kongresi, Antalya 2010.

18. Piko BF. Burnout, role conflict, job satisfaction and psychosocial health among Hungarian health care staff: a questionnaire survey. Int J Nurs Stud 2006; 43: 311-8.

19. Türkiye'de Tabip Odalarına Kayıtlı Olan Bir Grup Hekimde Tükenmişlik Sendromu ve Etkileyen Faktörler. Ankara. TTB yayınları, Ankara 2005. 
20. Suzuki E, Saito M, Tagaya A, Mihara R, Maruyama A, Azuma T, Sato C. Relationship Between Assertiveness And Burnout Among Nurse Managers. Jpn J Nurs Sci 2009; 6: 71-81.

21. Kelleci M, Gölbaşı Z, Doğan S, Ata E, Koçak E. The relationship of job satisfaction and burnout level with quality of life in hospital Nurses. Cumhuriyet Tip Derg 2011; 33: $144-52$.

22. Demir A. Hemşirelikte tükenmişliğe genel bakış. Atatürk Üniversitesi Hemşirelik Yüksekokulu Dergisi 2004; 7. 